\title{
Tensiones del sujeto entre lo instituido y lo instituyente. Del Frente Nacional a la Constitución de 1991*
}

\author{
Édgar Fernández Fonseca' \\ Corporación Universitaria Minuto de Dios
}

Recibido: febrero 19 de 2014 - Revisado: abril 23 de 2014 - Aceptado: mayo 14 de 2014

Referencia para citar este artículo: Fernández-Fonseca, E. (2014). Tensiones del sujeto entre lo instituido y lo instituyente. Del Frente Nacional a la Constitución de 1991. Revista Cientifica Guillermo de Ockham, 12(1), 77-92

\section{Resumen}

El sujeto politizado es el objeto de reproducción del sistema político. Sin embargo, también es potencia para la emergencia del sujeto político cuando las prácticas sociales desnaturalizadas simbolizan el horizonte de acción de lo colectivo. El siguiente texto parte de la hipótesis de que la Constitución de 1991, como momento instituyente de la historia de Colombia, fue fruto de una red de tensiones socioeconómicas y político-culturales, que gracias al caleidoscopio de la contingencia permitió la emergencia del sujeto político. Por tanto, dará cuenta de las continuidades y discontinuidades que incidieron en la configuración de un sujeto politizado previo al sujeto del momento instituyente de la Carta Magna de 1991, particularmente las incubadas durante el periodo histórico conocido como el Frente Nacional. La asepsia partidista, el discurso prescriptivo y la crítica y acomodamiento al régimen, se constituyen en las estrategias discursivas por las que fue instituido el sujeto polititizado.

Palabras clave: Sujeto politizado, historia de Colombia, cultura política

\section{Tensions the subject between the instituting and the instituted. Of the National Front to the 1991 Constitution.}

\begin{abstract}
The politicized subject is the subject of reproduction of the political system. However, it is also power for the emergence of the political subject when denatured social practices symbolize the skyline of the collective action. The hypothesis of this paper is that the Constitution of 1991 as instituting moment in the history of Colombia was the result of a network of socio-economic and politico-cultural tensions, thanks to Kaleidoscope contingency allowed the emergence of the political subject. Therefore, you will notice the continuities and discontinuities that affected the configuration of a politicized subject prior to the subject of instituting moment of 1991 Magna Carta, particularly incubated during the historical period known as the National Front. Partisan aseptic prescriptive discourse and critique and accommodation scheme constitute the discursive strategies by which it was instituted polititizado subject.
\end{abstract}

Keywords: Politicized subject, Colombian history, political culture

* Este artículo es producto del proyecto de investigación El sujeto politizado en la segunda mitad del siglo XX: Un análisis al Frente Nacional.

1. Magíster en Investigación Social Interdisciplinaria de la Universidad Distrital Francisco José de Caldas. Docente de la Corporación Universitaria Minuto de Dios y de la Secretaría de Educación de Bogotá. Miembro del grupo de investigación gibs. La correspondencia sobre este artículo debe ser dirigida a Transversal 63 \#68B-90 Sur. Manzana 3, Casa 35 Barrio Casagrande, Bogotá. E-mail: edferfon@gmail.com. 


\section{Introducción}

Comprender la cultura política de los colombianos en el contexto actual implica, por un lado, develar las estrategias, mecanismos y dispositivos de poder utilizados en la construcción de los sujetos que la componen; y por el otro, desentrañar los modos y resistencias por las cuales dicho sujeto resignifica los enunciados que pretenden convertirlo en objeto acabado. Así pues, la mirada está puesta en la red de continuidades y discontinuidades que se teje alrededor de la figura del sujeto politizado, específicamente en el andamiaje de la identidad y unidad nacional caracterizadas por lo educativo. El texto indaga por la construcción enunciativa del sujeto politizado en Colombia a través de prácticas discursivas como las políticas educativas y las publicaciones seriadas de intelectuales de izquierda (1956 y 1978) que permitieron la emergencia del sujeto político del momento instituyente de 1991.

El sujeto político es fruto del acontecer. Es un eterno presente que fluye en la dialéctica del devenir. No es una figura acabada o terminada ni una esencia dada o identidad sustantiva, como pretenden los principios y preceptos de las ideologías nacionalistas de las élites en el Estado-nación amparadas en el paradigma de la razón moderna, sino que por el contrario, se hace posible en el entramado de relaciones históricas que lo configuran. De ahí que se defina más por las posiciones que ocupa en las interacciones entre lo instituido y lo instituyente y en las luchas por la conformación del orden social, que por el sustancialismo ontológico que hace de él una figura acabada caracterizada por la razón, la libertad, la voluntad y la capacidad de conocer la verdad de lo real en sí misma (De la Fuente \& Messina, 2003).

La mirada del sujeto político como acontecer da cabida al sujeto politizado; es decir, como potencia que permite la emergencia del primero. Por tanto, en el sujeto politizado se establecen las primeras luchas y tensiones del sujeto como individuo y un "nosotros" como colectivo, así como todas las estrategias, mecanismos y movilizaciones que pugnan por posicionar al sujeto en un lugar de enunciación.

El propósito de esta pesquisa no es otro que abrir el horizonte de posibilidades para comprender eso que nos hace ser lo que somos. No es una historia de la segunda mitad del siglo XX en Colombia ni mucho menos del Frente Nacional -aunque la mirada esté puesta en este fenómeno de la historia política del país-, sino un análisis de los enunciados orientados a la configuración de la identidad nacional con el fin de entender cómo, a través de la configuración de un sujeto politizado ya sea como proyecto o resistencia al régimen hegemónico, se establece un contexto en el que emerge un sujeto que terminará por expresarse como sujeto político al situarse en nuevas prácticas sociales y discursivas en el entramado de la cultura política de los colombianos.

El abordaje al fenómeno conocido como Frente Nacional se debe a la particularidad que representa en los procesos de unidad nacional llevados a cabo en el país durante la segunda mitad del siglo XX, y que a su vez posibilitaron el restablecimiento del orden político durante su última década (Ayala-Diago, 1997; 2008). No obstante, pese a que la historiografía política tradicional establece que el Frente Nacional perduró dieciséis años (1958-1974), son varios los autores que sostienen que esta periodización obedece más a la organización legal y jurídica del gobierno de coalición que a la alternancia bipartidista, pues esta ya era un hecho en los principales gremios económicos del país. Por tal razón, se propone como periodización los años transcurridos entre 1956 y 1978, dado que permiten dar cuenta no solo de las prácticas bipartidistas presentes en la élite gremial y política de la nación, sino de los esfuerzos por configurar un determinado sujeto en lo político.

Se parte de la sospecha de que la Carta Magna de 1991 no es fruto de un proceso arbitrario ni esporádico, sino de un viraje y una reacomodación de las fuerzas políticas tanto hegemónicas como emergentes. Por tanto, una mirada de la historia social y política de Colombia de la segunda mitad del siglo XX y en particular del suceso conocido como Frente Nacional, permite dar cuenta -a modo de hipótesis- que en ese periodo se configuró el escenario propicio para un sujeto politizado que, como potencia, permitió la emergencia del sujeto político que transformó no solo el orden constitucional sino las prácticas políticas tradicionales.

\section{Metodología}

El horizonte metodológico sobre el que se forjó esta praxis académica pertenece a la investigación de tipo documental y recurre a algunas herramientas propias del análisis arqueológico. Si bien esta investigación implica fuertes retos y algunos determinismos y es propensa a caer en solipsismos, el esfuerzo que aquí se presenta busca la reflexividad acerca de una serie de formaciones discursivas que han mediado en la conformación de la cultura política de los colombianos. Esto con el fin abrir el abanico de posibilidades para que a partir de los procesos comprensivos sobre los fenómenos sociopolíticos, se puedan trazar perspectivas de transformación del orden instituido. En consecuencia, la construcción del objeto

$\varangle$ Universidad de San Buenaventura, Cali - Colombia 
de estudio interdisciplinar en la investigación social conlleva la apropiación de una metodología rigurosa y a la vez flexible que le permita no solo la recopilación de la información (descripción y caracterización), sino también el análisis detallado (interpretación y comprensión). En este sentido, la rigurosidad demanda constancia y tenacidad y la flexibilidad requiere adaptabilidad y cambio, soportes necesarios para que la investigación sea un ejercicio dinámico de reconfiguración y autoconstitución. La investigación debe apuntar no solo a la comprensión de un fenómeno social sino igualmente a su transformación.

La unión con la perspectiva arqueológica se explica porque entender "eso que hace ser lo que somos" bajo el matiz de la cultura política es el principal dinamizador de esta investigación. En este sentido, el enfoque metodológico permite analizar algunas de las prácticas discursivas que dan cuenta de la ontología histórica ${ }^{2}$ de la cultura política de los colombianos.

La arqueología no es una historia de los pensamientos, las representaciones y los imaginarios que pueden leerse en los discursos. No es un método de lectura alegórica que considera los monumentos como documentos en los que las voces del pasado pueden ser oídas e interpretadas. No se trata de una exégesis de los documentos (Hernández, 2010, p. 47). Por el contrario, la perspectiva arqueológica busca contribuir al análisis de los sistemas de discursividad en su dispersión y de los acontecimientos enunciativos que permiten identificar la unidad de un discurso mediante sus reglas de formación.

La mirada arqueológica de los documentos históricos no interpreta la voluntad individual del autor y rechaza cualquier análisis que se reduzca a las intenciones o capacidades de individuos empíricos. Por el contrario, "considera el discurso en su materialidad, en tanto producto de prácticas sociales concretas, entramadas en dispositivos concretos y busca mostrar cómo en ellos, los sujetos son fabricados" (De la Fuente \& Messina, 2003 , p. 6). Para Foucault, la arqueología responde a la necesaria ordenación de la lectura de los enunciados, por tanto estos se constituyen en la unidad básica de su estudio. La arqueología se propone "la descripción pura de los acontecimientos discursivos como horizonte para la búsqueda de las unidades que en ellos se forman (Foucault, 2007, p. 45).
La mirada se centró, por una parte, en las políticas educativas producidas durante el Frente Nacional y en las memorias de algunos de sus ministros de educación (desde 1956 hasta 1978), con el fin de identificar las principales estrategias y mecanismos que se establecieron en aras de construir y definir un sujeto en lo político en consonancia con los procesos de modernización e industrialización que vivía el país por entonces. Por otra parte, en las reacciones, discusiones y orientaciones que en el ámbito académico producía la intelectualidad progresista de la época y que tomaba cierta distancia tanto de las políticas del Gobierno como de los grupos y movimientos de izquierda que habían encontrado en la vía armada un medio para el reconocimiento social y político. Se revisaron dos publicaciones seriadas y dirigidas por reconocidos académicos y pensadores de izquierda colombianos como lo fueron Nicolás Buenaventura (Estudios marxistas: revista colombiana de ciencias sociales) y Estanislao Zuleta (Estrategia: revista de crítica contemporánea). Los años que serán revisados comprenden de 1962 hasta 1978. Esta mirada permitirá describir las maneras como dos modalidades discursivas, a saber, las políticas educativas y las publicaciones seriadas, se constituyen en elementos dinamizadores para la configuración discursiva de un determinado sujeto en lo político.

No se puede perder de vista que a pesar de todas las excepciones del caso y de las tensiones que de allí surgen, muchas veces las políticas educativas son el puente que comunica lo ideal con lo real. Aquella imagen del mundo idealizada se materializa en la puesta en marcha de la política pública. Pero también lo son los artículos publicados en revistas o libros como producto del análisis, la reflexión o la crítica de la realidad social. En este sentido, hacer un seguimiento a los enunciados que configuran una imagen de sujeto permite no solo interpretar el universo de idealizaciones que la clase política y los intelectuales poseen sobre los ciudadanos, sino también los modos como estos enunciados facultan la emergencia de nuevas posibilidades para la acción.

\section{Resultados}

Si bien el sujeto politizado es el objeto de reproducción del sistema político, también es potencia para la emergencia del sujeto político cuando las prácticas sociales

2. La ontología del presente -como ontología crítica de nosotros mismos- no es un cuerpo teórico ni un conjunto de conocimientos durables y estables en el tiempo. No es tampoco un estudio sino fundamentalmente un modo de encarar la vida y una forma de mirar el presente. Es una actitud filosófica "en la que la crítica de lo que somos sea al mismo tiempo análisis histórico de los límites que se nos imponen y experimentación de la posibilidad de transgredirlos" (Foucault, 1986, p. 36). 
desnaturalizadas simbolizan el horizonte de acción de lo colectivo.

Como potencia, el sujeto politizado se encuentra en el centro del debate que provoca la tensión entre lo instituido y lo instituyente, puesto que no solo es funcional a la reproducción del sistema político sino también a las prácticas sociales que permiten transformarlo. Como unidad biológica, el individuo ingresa al sistema político a través de la socialización política y se constituye como sujeto politizado, sedimento en potencia de la socialización política. Mediante la socialización, adquiere pautas de orientación cognitivas, afectivas y valorativas propias del sistema al que pertenece, esto es, su cultura política, lo cual no implica que una vez culmine su socialización se configure en un sujeto acabado y finalizado, puesto que esta dura toda la vida. Mediante su politización, la socialización política sitúa al sujeto en el horizonte de lo político y sus experiencias, sus prácticas y sus proyectos colectivos terminan por posicionarlo y convertirlo en actor, es decir, en sujeto político. De ahí que este no emerge de la nada, puesto que es en la potencia que le ofrece el sujeto politizado que surgen las posibilidades para su realización.

El sujeto politizado es potencia, entendida esta como posibilidades de ser y ello significa que nunca está acabado o concluido. Previo al sujeto político yace el sujeto politizado; es decir, un sujeto que posee todas las posibilidades de ser político, de asumir su propia existencia en un colectivo. Al sujeto politizado se llega a través de los procesos de socialización política. Cada sistema político tiene sus propios dispositivos y mecanismos que efectúan la socialización, orientados hacia la preservación y conservación del régimen. Por ejemplo, la ideología cuando está volcada hacia la legitimación o la integración del orden existente, busca mantener y preservar el orden social (Rojas-Ruiz $\&$ Camacho, 1975). No obstante, en su interior se encuentran espacios de tensiones y luchas que dan cabida a la utopía o la poiesis colectiva que intensifica las tensiones dentro del régimen político y permiten el posicionamiento a partir de lo alternativo del sujeto (que no es totalmente funcional al régimen). En las utopías yacen los espacios del no-lugar para la emergencia de nuevas posibilidades de acción. En ambos aspectos existe un sujeto del enunciado que en plano de lo político es el sujeto politizado. Los sistemas políticos no son ajenos a estas tensiones y luchas. La creación y la reproducción convergen en los procesos históricos de las naciones y son los espacios para las continuidades y las discontinuidades. En tal sentido, la historia social y política de Colombia en la segunda mitad del siglo XX no fue ajena a esta situación.
La historia no es extraña a las disputas por la conformación del orden social, puesto que en esta se concentran las tensiones entre lo instituido y lo instituyente, entre la política y lo político. De ahí que la historia social y política de Colombia no solo describe una sucesión de hechos que pertenecen al momento de lo instituido, sino que también en ella se encuentran los trazos que dan cuenta de lo político, esto es, de las luchas por la trasformación del orden social (lo instituyente). Particularmente, en la segunda mitad del siglo XX en el contexto del Frente Nacional se intensifica la lucha por lo político; es decir, se acentúa una atmósfera de cambio que absorbe principalmente la esfera de lo cotidiano. Durante este periodo, el país vivió los cambios socioeconómicos y político-culturales más pronunciados y significativos, uno de cuyos principales movilizadores fueron las transformaciones llevadas a cabo en el escenario mundial. El historiador Eric Hobsbawn describe con agradable profundidad cómo entre 1945 y 1990 el mundo pasó a ser predominantemente urbano y producir un gran desplazamiento poblacional hacia las ciudades que trastocó los modos de pensar, sentir y valorar de las personas. Lo anterior, unido a la creciente facilidad para acceder a la educación particularmente universitaria, afectó sin lugar a dudas los modos de hacer y sentir la cultura y la política.

Cuando el campo se vacía se llenan las ciudades. El mundo de la segunda mitad del siglo XX se urbanizó como nunca. Casi tan drástico como la decadencia y caída del campesinado y mucho más universal, fue el auge de las profesiones para las que se necesitaban estudios secundarios y superiores. La gran expansión económica mundial hizo posible que un sin número de familias humildes -oficinistas y funcionarios públicos, tenderos y pequeños empresarios agricultores y, en occidente hasta obreros especializados prósperos- pudiera permitirse que sus hijos estudiasen a tiempo completo (Hobsbawm, 2010, p. 300).

Colombia no fue ajena a esta dinámica que intensificó la movilización masiva de miles de campesinos hacia los centros urbanos -especialmente las ciudades medianas- atraídos por los procesos de desarrollo industrial y tecnificación agrícola. Así pues, se crean las condiciones adecuadas para la configuración del sujeto politizado mediante una práctica discursiva que orienta a ese individuo que se sumerge en la dinámica y a la vez volátil vida de lo urbano.

La historia social y política de Colombia a lo largo del siglo XX se mueve en la corriente inclusión-exclusión. De esta manera, quienes detentan el poder establecen una serie de mecanismos para alejar a su adversario político del espacio de la gobernabilidad nacional. De ahí que 
antes del establecimiento del Frente Nacional se pueda afirmar que la administración del poder estuvo fraccionada en regímenes de gobierno que actuaban de acuerdo con intereses partidistas (liberales y conservadores). Sin embargo, si bien existían diferencias discursivas e ideológicas entre liberales y conservadores estas no eran lo suficientemente antagónicas, dado que sus líderes compartían y frecuentaban los mismos clubes sociales o universidades (¡hasta los liberales iban a misa!) y era el pueblo como tal el verdaderamente excluido.

Aunque en la historiografía tradicional se haya matizado el hecho de que los liberales eran en sus raíces comerciantes y los conservadores latifundistas, no se puede reducir la actividad económica a la filiación política. Como miembros de la élite detentaban el poder político y lo administraban de acuerdo con sus intereses, por tanto la pronunciada división partidista de mediados del siglo XX responde no solo a las luchas que se dan por la administración de lo instituido, sino también como mecanismo para la preservación y el mantenimiento de la exclusión sociopolítica del pueblo. Según Fernando Guillen Martínez, el periodo de la violencia no se explica solo a partir del antagonismo partidario de mediados del siglo XX, sino que obedece igualmente a la exclusión política sufrida por el pueblo colombiano a lo largo de su historia:

La violencia de los ańos cincuenta aparece muy ligada a las huellas de la encomienda y hacienda, la geografía de la violencia coincide con las zonas fuertes de estructura hacendataria, mientras que donde esta fue débil (como la costa atlántica) la violencia apenas tuvo importancia (Guillen, 1996, p. 17).

La reacción del pueblo ante la muerte del líder liberal Jorge Eliécer Gaitán el 9 de abril de 1948, se constituye en una forma de expresión social y política ante esa exclusión hegemónica. Con los años y pese a los esfuerzos de pacificación, la estructura hacendataria del país y la violencia imperante fomentan el surgimiento del bandolerismo que se convierte en una forma de expresión fehaciente del excluido.

Es incuestionable que el bandolerismo fue una manifestación social y política. La característica más significativa del "bandolerismo social" propiamente dicho es la de que está reconocido, tolerado e incluso respaldado localmente y no podría sobrevivir durante largo tiempo -al menos en las áreas rurales-sin el reconocimiento, la tolerancia y el respaldo que le brinda la población (Sánchez \& Meertens, 2006, p. 204).
A mediados del siglo XX, la precaria situación de las áreas rurales aviva una atmósfera de inconformidad social que sirve de caldo de cultivo para la configuración de un tipo determinado de sujeto en lo político. Es en la lucha por la tierra que se abona el terreno para una posible politización. No obstante, esta acción venía siendo potenciada desde la década de los treinta cuando el Partido Liberal abanderó estas luchas, legitimado socialmente por los esfuerzos de los gobiernos liberales -sobre todo de Alfonso López Pumarejo- y la reforma agraria. Con el establecimiento del régimen y los procesos de desplazamiento y urbanización que el desarrollo industrial y la tecnificación agrícola desataron, las luchas por la tierra dieron un viraje y terminaron convirtiéndose en luchas por la ciudad.

Ante la situación de inestabilidad social y política se establece la dictadura de Gustavo Rojas Pinilla -con el beneplácito del Partido Conservador y la Iglesia- como una posibilidad de pacificación y reconciliación de la nación, materializada en los acuerdos de paz firmados con las guerrillas liberales de los llanos orientales. No obstante, luego de cuatro años fuera del Gobierno y ante el creciente poder popular de Rojas, las élites políticas desean retornar al poder. Mediante los diálogos entre Alberto Lleras Camargo y Laureano Gómez en España (Pacto de Benidorm firmado el 26 de julio de 1956 y el acuerdo de Stiges firmado un año más tarde) se pretendía conciliar las diferencias que por años habían alimentado la violencia. El fin de la dictadura de Rojas dio lugar a la Junta Militar que sirvió de transición al establecimiento del régimen bipartidista.

No obstante, el Frente Nacional continuó la política de exclusión que años atrás caracterizó a los partidos políticos. Las élites recuperaron el poder y buscaron centralizar el país haciendo un llamado a la unidad nacional; sin embargo, pese a los esfuerzos aún quedaban amplios sectores de la población por fuera, incluidos los disidentes del Partido Liberal, liderados por Alfonso López Michelsen en el MrL, el Partido Conservador, dirigido por Gilberto Álzate Avendaño y el Partido Comunista, que durante el régimen no logró aglutinar a la izquierda.

El Frente Nacional ${ }^{3}$ como política de coalición, suprimió las luchas por la administración de lo instituido, esto es, de la política y las redujo a la formación de clientelas que luchan no por la administración de lo instituido, sino por el mero intercambio de favores para mantener su lugar de poder. En este sentido, la anulación

3. Presidentes del Frente Nacional: Alberto Lleras Camargo (liberal 1958-1962), Guillermo León Valencia (conservador 1962- 1966), Carlos Lleras Restrepo (liberal 1966-1970) y Misael Pastrana Borrero (conservador 1970-1974). 
de la política como campo de luchas que resignifican el horizonte de lo instituido hizo posible la emergencia de la inconformidad y creó el espacio de dislocación que terminó por desbordar al régimen. Es decir, viabilizó la configuración del sujeto politizado como potencia que haría posible al sujeto político, quien ante la exclusión busca una transformación del sistema político que tuvo en la Constitución del 91 su consecuencia más visible. Ante la ausencia de un proyecto de cambio acorde con las necesidades sociohistóricas del momento por parte de la oposición al régimen y la imposibilidad de una reforma, surge la figura del sujeto politizado como aquel que en medio de la tensión se acomoda al escenario y termina por desbordar el régimen, permitiendo así la emergencia del sujeto político.

El bipartidismo no es ajeno a la historia social y política de Colombia y durante la segunda mitad del siglo XX el Frente Nacional influyó notablemente en los procesos sociopolíticos de la nación (Hartlyn, 1993). Una revisión al sujeto politizado en ese periodo lo evidencia como totalmente cruzado por este fenómeno. Sin entrar a discutir la precisión temporal del pacto bipartidista (fijado entre los años de 1958 y 1974), se propone como periodo de análisis a la luz del régimen de coalición el transcurrido entre los años de 1956 a 1978, dado que antes de la instauración legal del régimen se daban prácticas de alternancia del poder de parte de la élite económica, especialmente de agremiaciones como la Andi, Fenalco, Fedegán y la Asociación de Agricultores de Colombia, entre otras. Por otra parte, se firma el pacto de Benidorm en el cual los principales líderes partidistas representados por Alberto Lleras Camargo (liberales) y Laureano Gómez (conservadores) sientan las bases para la configuración del Frente Nacional, ello aunado al hecho de que hacia mediados de la década de los cincuenta se presenta un viraje en la forma de gestionar las prácticas y los discursos orientados hacia la configuración del sujeto, con un especial énfasis en las políticas educativas orientadas a la configuración de la identidad y unidad nacional (Moreno 1982). El ambiente de progreso y desarrollo que vive el país crea un espíritu de renovación que se materializa en la formulación del primer plan quinquenal de educación y en la creación de la oficina de planeamiento educativo del Ministerio de Educación Nacional.

La política educativa es al tiempo la teoría y la práctica del Estado en materia de educación. Inmerso en la política educativa yace un sujeto de la enunciación que se transforma en el sujeto por politizar. A su vez, se presenta la inconformidad y divergencia contra el Estado, coyuntura que posee un sujeto de la enunciación que busca ser politizado en consonancia con unos fines o ideales previstos, como la reforma o transformación del orden dado. La Colombia de mediados de los cincuenta y finales de los setenta no es ajena a esta tendencia, la cual se concreta en esfuerzo por modernizar el Estado merced al rápido crecimiento económico que experimenta el país y al vertiginoso ritmo de cambio de la economía mundial.

Los tres momentos o periodizaciones obedecen a cambios en las interacciones entre lo oficial y lo no oficial y no a la unificación de criterios comunes. Por tanto, la mirada está fijada en las relaciones establecidas entre la formulación, la aplicación y la reacción a la política educativa orientada a la configuración de un determinado tipo de sujeto politizado y sus puntos de encuentro y desencuentro.

El sujeto del enunciado es el sujeto politizado y las unidades discursivas que lo producen permiten entrever la conformación de una serie de estrategias y mecanismos que inciden en su configuración. La modernización trae consigo el espectro de la renovación y con base en él se configura una serie de modalidades discursivas en lo político orientadas a un determinado sujeto. De esta forma, entre 1956 a 1978 se efectuaron una serie de esfuerzos tanto oficiales como privados por politizar al sujeto. Ante el asomo de la contingencia, se estableció un ambiente de cambio y reforma que buscaba ser materializado en la proyección de nuevos ciudadanos en consonancia con los ideales de progreso y desarrollo económico que guiaban la nación. En este sentido, mediante las siguientes tres estrategias discursivas operó la politización de los sujetos.

\section{La asepsia partidista}

Se caracteriza por el esfuerzo orientado hacia la limpieza de toda huella de violencia partidista que había incubado en la memoria colectiva unos odios políticos cuya verdadera razón de ser era la exclusión sociopolítica de parte de la élite hegemónica. Los lugares de producción del sentido de lo político se encontraban reducidos y poco a poco fueron cooptados por formas de estigmatización y eliminación ancladas en discursos dicromáticos y pseudorreligiosos. La atroz experiencia de la violencia y la amenaza de una creciente insatisfacción e inconformismo social producto del progresivo avance del desarrollo industrial, la tecnificación agrícola y la urbanización de la vida, condicionaron a la élite política para dejar en manos de la dictadura de Rojas Pinilla -cuidando, eso sí, que este no se le saliera 
de las manos- una posible solución y la instauración de un ambiente de paz, justicia y libertad.

En concordancia con la lógica modernizante, hacia 1956 son llevadas a cabo en el país un buen número de misiones internacionales cuyo objetivo era proyectar en la comunidad social un ambiente académico e investigativo que matizara, con el barniz de la objetividad y la neutralidad, la realidad social. Estas misiones se constituyen en el soporte para la formulación de políticas públicas (sobre todo en el campo de la educación y la economía) orientadas a la mejora administrativa del Estado, como lo fueron la planeación integral de la educación y la reforma administrativa de 1958.

Por su parte, el sujeto del enunciado permanece en el atolladero entre lo urbano y lo rural producto de la tecnificación del campo, la violencia y la carencia de un suelo donde cultivar. Se ve forzado - cuando no utilizado como campesino asalariado- a desplazarse y ubicarse en la periferia de la ciudad como obrero, coyuntura que crea las condiciones adecuadas para que la asepsia partidista encuentre en el discurso moralizante centrado en la solidaridad comunitaria y el rescate de los valores cívicos y patrióticos, un mecanismo para politizar a los sujetos a través de la ciudadanización de la vida. No se encuentra mejor trinchera para su defensa que el discurso orientado a fortalecer la unidad e identidad nacional a través del desarrollo y progreso económico. El obrero vinculado a la industria debe verse a sí mismo como gestor del propio desarrollo nacional, razón por la cual el sujeto del enunciado es el trabajador y el dispositivo para efectuar la ciudadanización es el aparato educativo, de ahí la necesidad de intervenir en las dinámicas que afectan la producción y la planeación educativa.

La asepsia aseguraba la limpieza de toda mancha de la violencia partidista, pero dejaba a la vista el verdadero problema que explicaba los odios políticos de antaño. La exclusión política escondía una gigantesca desigualdad social amparada en una sociedad predominantemente rural y campesina paradójicamente sin tierra y suelos propios para labrar, tensión que se profundiza cuando ejércitos enteros de campesinos llegan a las periferias de las ciudades y se asientan allí en busca de nuevas oportunidades. Ante esta compleja situación, emerge la segunda estrategia para la politización del sujeto.

\section{El discurso prescriptivo}

Ante la incapacidad del Estado por llenar los vacíos de lo social que las demandas de crecimiento urbanístico crean, se configura un espacio de inconformidad que origina un conflicto de clases. ${ }^{4}$ Este espacio es intervenido tanto por las fuerzas de lo instituido como por las que se oponen al régimen. Los nuevos sujetos dejan escuchar su voz en el murmullo de los puntos de dislocación que se producen ante las demandas sociales y las acciones solidarias comunitarias que desbordan el régimen. Tanto el Gobierno como la oposición reconocen que existe un sujeto por politizar, por lo cual deben generar acciones de intervención prescriptivas que les permitan su posible adhesión.

Hacia 1964, la acción del Estado se dirige a implementar y aplicar las políticas diseñadas por los expertos internacionales. Las fuertes tensiones sociales se acrecientan día a día en los barrios populares y obligan al Estado a llevar a cabo acciones encaminadas a menguarlas.

El principal rasgo del discurso prescriptivo es el cambio de orientación de las manifestaciones discursivas sobre la violencia política. Hacia mediados de 1940 y 1950 en pleno auge de la Violencia, predominaban abiertamente las diferencias y los conflictos de partido que no eran más que el velo que ocultaba el verdadero problema. El conflicto entre liberales y conservadores era solo la punta de iceberg que escondía décadas de exclusión política y acrecentamiento de las diferencias sociales. No obstante, con la puesta en marcha de la asepsia partidista el velo es corrido y queda al desnudo la verdadera razón de la lucha partidaria. Al limpiar al sujeto de toda huella dicromática con la que se explicaba la violencia, no queda más que las fuertes diferencias sociales que lo aprisionan, las cuales son reforzadas a través del despojo de la tierra, el crecimiento urbano y los procesos de industrialización y tecnificación agrícola y avivadas por el posicionamiento y consolidación de la élite financiera. Así pues, a principio de los sesenta las crecientes demandas sociales robustecen las diferencias ya existentes, situación que pone al sujeto en situación de cuestionar el entramado socioeconómico y político-cultural en el que se encuentra.

Desde la perspectiva oficial y la no oficial, se reconoce la existencia de un sujeto por politizar, por tanto se de-

4. Según el profesor Leopoldo Múnera "[...] durante Frente Nacional se presentan cuatro procesos simultáneos que afectaron la vida social y política de la nación entre los que se encuentra la metamorfosis de la violencia politica que pasa de un conflicto partidista a uno clasista. Los otros tres procesos tienen que ver con la superación de la dualidad contradictoria del bipartidismo como elemento de unificación nacional y polarización política, la redefinición de la relación entre coerción directa y consenso dentro de la hegemonía política colombiana y en consecuencia del papel institucional de las fuerzas militares, y la restructuración por fuera de las instituciones políticas de la acción colectiva popular y de las organizaciones que impugnan el bipartidismo" (Múnera, 1998, p. 106). (Las cursivas son mías). 
ben generar acciones de intervención prescriptivas que le permita su posible adhesión. De ahí que el discurso prescriptivo, como politización, persigue las formas sobre las que se debe intervenir en el sujeto, bien a partir de lo oficial o de lo no oficial. Los mecanismos para ejecutar esta acción recaen en los esfuerzos por urbanizar y proletarizar a los individuos.

En las juntas de acción comunal se busca reducir las tensiones sociales y se recurre a la urbanización de la vida como el modo por el cual el discurso prescriptivo toma sentido. Aquí solo se requiere la figura del experto o funcionario público para que aplique e implemente la política previamente diseñada. Así pues, se llega a los barrios, se llenan encuestas, se alfabetiza a la gente y de paso se asegura la intervención.

En este mismo sentido pero desde la orilla opuesta, la izquierda trata de llegar a este mismo tipo de gente de igual manera mediante un discurso prescriptivo, pero buscando su proletarización amparada en la lógica del canon marxista y soviético. Sobresale la figura del intelectual que inconforme con las formas de hacer investigación en el país pretende acercarse y comprometerse más profundamente con las comunidades que estudia. La relación entre la teoría y la práctica configura la tensión que el discurso prescriptivo, a través de las figuras del experto o funcionario público y del intelectual de izquierda, trata de resolver.

Con la puesta en marcha del discurso prescriptivo, la planeación estratégica asoma en el horizonte como guía de la politización. El sujeto del enunciado es el obrero inserto en un plan o programa que mejore su calidad de vida y en el que la izquierda también pugna por crear una conciencia revolucionaria que conduzca a la transformación y a la construcción de una nueva vida. Por ello, en ambos yace la esperanza de un "nuevo hombre" que será el encargado de hacer un nuevo país.

La urbanización creciente y las demandas sociales que esta conlleva, obligaron al Estado a concebir acciones orientadas a su satisfacción. Sin embargo, su falta preparación para la ejecución de políticas sociales de gran envergadura y ante los compromisos internacionales que ha suscrito, como la Alianza para el Progreso o la Conferencia de Punta del Este de 1967, recurre a la figura del agente o experto internacional para que direccione la puesta en marcha de las políticas. Agentes de origen norteamericano como los Cuerpos de Paz llegan al país con la misión de ayudar en áreas como la salud, la educación y el trabajo.

En el discurso prescriptivo no solo se resalta la figura del agente internacional, sino también la del tecnócrata o funcionario especializado que adquiere un mayor margen de maniobra a mediados de la década de los sesenta y hace más eficiente el sistema. La reforma administrativa llevada a cabo por Carlos Lleras en 1968 es, sin duda, un viraje en lo instituido que desplaza al político tradicional de algunos espacios de la administración para dar lugar al paquidérmico paso de la burocracia clientelista.

Las dos figuras descritas anteriormente -el agente internacional y el tecnócrata- se constituyen en los entes responsables de aplicar el discurso prescriptivo. Nadie mejor que el funcionario para mostrar resultados concretos y asegurar procedimientos de intervención de tipo social en los sujetos que lo requieren. El sujeto del enunciado es el obrero que se instaura como el sujeto por intervenir. $\mathrm{Si}$ bien aun se debe ciudadanizar a las personas, el esfuerzo de la politización ya no estará centrado en la moral y el civismo sino en una formación para el trabajo que no solo contribuya al desarrollo y progreso de la nación, sino que beneficie su propia vida. Al corriente de esta lógica, el discurso prescriptivo como forma de politización en lo oficial se desarrolla a través de la urbanización de la vida, lo que implica el apaciguamiento de las tensiones sociales mediante la participación limitada de los individuos en instituciones como las juntas de acción comunal o mediante la creación de espacios de formación para el trabajo subordinado.

Se diseñan planes y programas sociales -en educación y salud principalmente- para ser aplicados en las grandes y medianas ciudades cuyo fin es mermar la creciente inconformidad social. De igual manera, la acción comunal se fortalece en la medida en que se constituye en un instrumento de apaciguamiento de las tensiones sociales y los espacios de intervención, a saber, la familia, la empresa y el barrio se configuran como medios a través de los cuales se moviliza el obrero, que de esta manera es reducido al círculo urbano de la vida privada y convertido en un sujeto pasivo del proceso histórico.

Las actividades de planeación se dirigieron a introducir reformas en la administración educativa, a modernizar la universidad, ampliar la cobertura del sistema escolar y a iniciar programas de educación funcional de adultos con capacitación para el trabajo. Durante el Frente Nacional el planeamiento de la educación se enfocó hacia la formulación de diferentes innovaciones y hacia el diseño de estrategias para implantarlas. Entre estas, la introducción del sistema INEM, basadas en las experiencias de la Escuela comprensiva americana, y de las concentraciones de desarrollo rural, inspiradas en las recomendaciones de la OIT para el logro del pleno empleo, se constituyeron 
en importantes esfuerzos, del Departamento Nacional de Planeación, para hacer operar más eficientemente el sistema educativo (Zúníga, 1979).

A pesar del esfuerzo del Estado por intervenir según la prescripción que la política tecnocrática señalaba, las crecientes demandas sociales y su ineficacia para satisfacerlas generan un ambiente de inconformismo que rápidamente es aprovechado por sectores de oposición. Particularmente, el Partido Comunista fortalece una serie de estrategias orientadas a la configuración de un determinado sujeto y desde la lógica de lo no oficial ejecuta acciones orientadas a su politización. En esta perspectiva, el sujeto del enunciado es el mismo que no sale del laberinto entre lo urbano y lo rural. La politización opera mediante estrategias encaminadas a la proletarización de los individuos y a su toma de conciencia en aras de posibilitar procesos revolucionarios que transformen el orden instituido.

Generar una toma de conciencia proletaria es la meta más sentida de la politización, por tanto se deben intervenir los individuos y sus vidas. Para ello se debe llevar a cabo una planeación que se materializa en el programa del partido y describe teleológicamente el deber ser de la acción revolucionaria. La intervención no oficial se desenvuelve y efectúa en el marco de lo prescrito; es decir, en el plano de lo direccionado y recetado. Aunque ideológicamente se encuentre en oposición a las versiones oficiales, el discurso prescriptivo se hace una vez más visible, tal como lo señala Nicolás Buenaventura:

El método marxista requiere un investigador realmente comprometido que tome partido en la práctica de la cual se ocupa. El método marxista se realiza completamente o se vuelve una realidad solo en la medida en que se encuentre cómo llevar la práctica obrera y popular a un nivel de conciencia cada vez más alto, mediante la generalización y aclaración constante de esa práctica (Buenaventura, 1973, p. 6).

Las diferencias que experimentaba la izquierda hacia mediados de los sesenta, provenían del dilema que la aquejaba, consistente en orientar su práctica revolucionaria hacia la democratización mediante el parlamentarismo y la lucha de autodefensa -tendencia abanderada por los viejos comunistas- o iniciar un proceso insurreccional inmediato que trajera consigo la revolución en el corto plazo, de acuerdo con el esquema cubano (esta última gozaba de especial preferencia en algunos jóvenes militantes).

En medio de este escollo se presentan varias escisiones que terminan por dispersar en varios frentes ideológicos la lucha revolucionaria, situación que suscita la necesidad de reorientarla y alejarla de este atolladero. Así, se resuelve la tensión entre teoría y práctica mediante una tercera tendencia que apunta a comprender la realidad social merced a una mirada no centrada en la reducción de la relación individuo-sociedad o en la imposición de una de las partes sobre la otra, sino en la conformación de nuevos modos de proximidad al conocimiento del mundo social que permitan una toma de conciencia en los sujetos y por ende la trasformación del orden social.

No se trata solo de seguir el canon marxista bajo las banderas de la plaza roja o la identificación con la experiencia cubana, sino ampliar el espectro de análisis sobre los objetos de estudio del mundo social, enriquecer la reflexión teórica de la mano con otras disciplinas y corrientes de las ciencias sociales y reorientar la praxis metodológica en el entramado social. Esta tendencia muestra sus reflexiones y resultados de investigación en publicaciones como Estrategia y Estudios marxistas, la primera de las cuales es de corte más intelectual y reflexivo y la segunda muestra un derrotero más práctico e investigativo.

Pese al esfuerzo, aún se mantiene la prescripción discursiva en el sujeto del enunciado y al igual que en la perspectiva oficial se busca politizar a través de la intervención directa. No obstante, la influencia metodológica de disciplinas como la sociología brinda un nuevo campo para la práctica investigativa. Una nueva generación de jóvenes estudiantes insatisfechos con los modos tradicionales de investigación busca un mayor acercamiento a las poblaciones con las cuales encuentra ciertos elementos comunes de insatisfacción social. De este contexto surge la figura del intelectual e investigador comprometido, en contraposición a la imagen del experto internacional y del tecnócrata predominante en la perspectiva oficial.

La politización del sujeto se efectúa por medio de un cambio en el abordaje metodológico y teórico a la hora investigar la realidad social. Se debe superar la tensión entre individuo y sociedad en los debates teóricos y reconocer que el individuo es un ser social, lo que haría del sujeto politizado un sujeto colectivo, determinado por su posición en un grupo social ya sea como obrero, campesino, estudiante, etc. "Es importante formar una conciencia revolucionaria que sea producto de la dialéctica entre estudiar y actuar. Esta unidad implica que la teoría debe ser íntimamente práctica y que la acción debe ser en si misma teórica” (Organización Marxista Colombiana, 1964, p. 167). El sujeto politizado es un sujeto alfabetizado.

El sujeto de la politización es el marginado, ya sea campesino asalariado o proletario agrícola. Por tanto, la práctica intelectual e investigativa es un compromiso político y debe recaer en la proletarización del sujeto. La 
politización opera gracias a la formación de una conciencia de clase revolucionaria, pero sin dejar de recurrir a un discurso centrado en la formación de la unidad nacional a partir la lucha revolucionaria de clase y la crítica al imperialismo. Para ello es necesario la conformación de cuadros revolucionarios capaces de guiar el proceso y que al igual que los "Cuerpos de paz" o consejeros y orientadores del Estado, son responsables directos de la politización. Sin embargo, el poco compromiso de la masa con la militancia política obliga al trazado de dos derroteros que marcan la politización: por un lado, centrar la acción en la configuración de una vanguardia revolucionaria que supere la tensión entre teoría y práctica; y por el otro, reconfigurar el horizonte del enunciado revisando el discurso monolítico que establecía la ruta procedimental para la revolución. Influenciada por las diferentes disciplinas y corrientes de pensamiento sobre el mundo social, la politización se va insertando poco a poco en un nuevo lineamiento prescriptivo que sin abandonar su orientación hacia la proletarización, amplía el espectro de análisis social recurriendo a disciplinas como la sociología, la historia, la economía y el psicoanálisis.

El esfuerzo de la acción no debe recaer en maniobras de clase de tinte meramente sindical, sino en acciones que apelen a la solidaridad humana -como las huelgas de hambre- $y$ abran paso a nuevos espacios para la emergencia del sujeto politizado. Los movimientos cívicos trascienden la esfera de la lucha revolucionaria y se asientan en lo humano y no exclusivamente en una cuestión de clase. Medina (1997) define los paros en Colombia como aquellas acciones cuyo objetivo son reivindicaciones comunes a amplios sectores de la población y suscitan un amplio respaldo de las masas. Señala además, que el paro se constituye en la forma más importante y organizada de los movimientos cívicos.

Frente al régimen general de ilegalidad o de excepción de la ley constitucional, que viene operando desde los tiempos de la violencia con el estado de sitio permanente, los paros cívicos, apoyados siempre en un gran consenso público, afirman constantemente la fuerza y la apariencia de una legalidad nueva expresada en la unidad de acción de toda la población trabajadora. [...] Los paros cívicos constituyen una modalidad de acción popular en pleno ascenso. Una modalidad que se viene expandiendo y generalizando con grandes perspectivas de influencia en el cambio social hacia la democratización del país (Medina, 1997, pp. 6-12).

Los movimientos cívicos permiten la emergencia del sujeto politizado, el cual a través de los paros cívicos, desborda la figura tradicional del proletario que se establecía en el molde soviético. Se proletariza, pero en este caso en atención a la solidaridad humana y no solo a factores de clase. Sobre un discurso prescriptivo que establece la validez de nuevas formas de movilización social, el sujeto del enunciado emerge en el espacio de las interacciones entre las demandas sociales y la resistencia al régimen.

Las luchas por el derecho a la ciudad son la principal causa de las movilizaciones cívicas y en estas subyacen acciones que permiten la irrupción del sujeto politizado. En la ciudad se reproducen las diferencias sociales y la segregación urbana que diezman los espacios de participación y aunque la acción comunal se presente como un lugar para el reconocimiento del sujeto, su montaje se configura bajo el andamiaje de la exclusión. Como reductora de la tensión social, no es más que una forma de control de las iniciativas de acción de la base popular y una reacción del Gobierno bajo el supuesto de que de una parte la situación de la masa rural y de los inmigrantes llegados a la ciudad podría producir perjuicios económicos muy grandes para la clase dominante.

El pueblo es tan numeroso, mayoritario en las ciudades, que sin organización comienza a presentar un frente común contra la segregación y las clases que la establecen. La apropiación de los suelos urbanos esterilizados por los especulados, se hace cada vez de manera más organizada, la defensa pasiva se hace presente en forma de movimientos espontáneos de la población urbana y la lucha por sobrevivir en los barrios obreros y los tugurios ha comenzado a crear la solidaridad colectiva (Urbano, 1970, p. 97).

En la ciudad, el sujeto del enunciado no solo es el obrero atado a la seguridad ontológica que su empleo le proporciona. También allí se encuentran conglomerados que se han venido constituyendo en sujetos por politizar y por tanto por proletarizar.

\section{Crítica y acomodamiento}

En los diferentes momentos de la politización del sujeto, el concepto de planeación educativa se va transformando en correspondencia con los cambios socioeconómicos del país. De una postura que ve la educación como un gasto (antes de 1955), se pasa a otra que la considera como una inversión productiva (hacia 1965) y luego a una tercera que espera de aquella asegure el máximo rendimiento interno (principios de los 1970). Esta caracterización de la educación como garantía de consolidar el máximo rendimiento interno de la nación, coincide con el tercer momento que incide en la configuración del sujeto politizado.

$86<$ Universidad de San Buenaventura, Cali - Colombia 
Al desplazar al sujeto del enunciado de un discurso prescriptivo centrado en la proletarización o urbanización de la vida ${ }^{5}$ en aras de contribuir a los ideales de progreso y desarrollo nacionales, a uno en el que él mismo se proyecta como un nuevo hombre que de la mano con la movilización colectiva fortalece al máximo el rendimiento interno del país, se forjó una tensión que terminó por hacer visibles dos elementos que aunque contradictorios en apariencia, no son más que polos opuestos que se complementan. Por un lado, no solo en reacción frente a las políticas educativas como la tecnología educativa o las reformas administrativas en educación, sino también contra la difícil situación social que vive el país (costo de vida), se refuerzan la crítica al régimen y las movilizaciones que las expresan, como los paros cívicos, las protestas sociales y las huelgas, las cuales a su vez coinciden con el desmonten legal del Frente Nacional. Por el otro, la acción paquidérmica del Estado ante las movilizaciones emergentes y las prácticas clientelistas, hicieron que el sujeto no solo se quedara anclado en prácticas que se reducían a meras críticas hacia el Gobierno, sino que recurriera a una especie de pragmatismo basado en el tráfico de influencias que facilitaba la consecución de objetivos. Es una doble conciencia del sujeto politizado expresada por una parte, en una crítica al Estado como resultado de la exclusión que lo caracteriza y de la lenta acción en beneficio de las comunidades; y por la otra, de acomodamiento a las pocas acciones que este desarrolle en beneficio de las comunidades.

Una de las características del líder comunal de los barrios populares es la posibilidad de participar en ese doble juego que para él representa la política (Torres, 1993). Las acciones colectivas, como la toma a la fuerza de terrenos para vivienda en las periferias de las ciudades o las movilizaciones que buscan la llegada de rutas de transporte al barrio y adoptan la forma de protesta cívica, contrastan con la reverencia y pleitesía que se rinde a los políticos locales para gestionar la consecución de los servicios públicos o la construcción de escuelas para el barrio. En este sentido, las formas de movilización social durante el régimen de coalición, basadas en la exclusión y en una menguada crítica al régimen, soportadas más en la indiferencia y la apatía que en la oposición abierta y reconocida, muestran cierta predisposición a la formación de un sujeto que en lo político se presta al doble juego camaleónico de la crítica y el acomodamiento.
El sujeto del enunciado no solo se reduce al obrero que cumplía un papel central en los dos momentos descritos anteriormente (asepsia partidista y discurso prescriptivo). Campesinos, estudiantes, independientes, madres cabeza de familia, intelectuales, profesionales y maestros, se constituyen como sujetos por politizar en cuanto se puede hacer de ellos una figura para el "hombre nuevo". El desmonte paulatino del Frente Nacional y la creciente movilización social, hacían posible pensar en un cambio social y el esfuerzo recaía en la politización del sujeto. Ya no era necesario recurrir solamente al individuo atado a la lógica de lo rural en la periferia de la ciudad ni mucho menos al obrero. La lucha recaía ahora en la formación de un nuevo hombre como forma de politización.

Las figuras encargadas de la politización continúan siendo los funcionarios de nivel de mandos medios y los intelectuales. La izquierda por su parte, se fortalece como el guía de la politización. Las experiencias socialistas soviética, cubana y china dividen una izquierda nacional atada a discusiones fútiles sobre la mejor manera de proceder en la causa revolucionaria. Las tensiones entre revisionistas, teóricos y practicistas no hacen más que agravar la división de la izquierda, ante la cual el intelectual se posiciona como un agente colectivo que busca resolver la tensión entre teoría y práctica revolucionarias, como ya se venía dando durante el discurso prescriptivo. La principal función del intelectual recaía en hacer entender a la inmensa masa la correspondencia entre sus propias aspiraciones materiales y la ideología de vanguardia. Tal y como lo mencionaba Buenaventura:

Lograr la conquista revolucionaria, conformarla y consolidarla requiere un esfuerzo intelectual colectivo, una integración de la fuerza física de masas con la fuerza ideológica en que la historia manifiesta a través de la inteligencia humana, como razón científica, el esquema de la nueva sociedad (Buenaventura, 1973, p. 6).

Sin embargo, el esfuerzo del intelectual no se reduce más que al estudio y la formación de cuadros revolucionarios y termina, en últimas, por fungir como intermediario entre él y la masa.

En esta misma lógica pero en la orilla opuesta, se encuentra el funcionario público que se encarga de convertir en planes y programas las políticas educativas. Más que un político opera como una suerte de intelectual tecnificado

5. Sobre la urbanización José Urbano señala: "Al borde de la ciudad, a las puertas de lo urbano viene a colocarse al subproletario, los habitantes de los tugurios expulsados del campo, atraídos a la ciudad por una forma de vida la cual, privilegio de un minoría, nunca podrán alcanzar. Rechazados de lo urbano por una organización social que voluntariamente los segrega y aísla como al cáncer de las ciudades” (Urbano, 1970, p.88). Este tipo de sujeto que se asienta al borde la ciudad es a quien se dirige el discurso orientado a politizar. Lo urbano se constituye en el dispositivo para politizar al sujeto que se asienta en los tugurios. 
que se echa sobre sus espaldas la parte ejecutoria de las políticas. La reforma administrativa de 1968 terminó por fortalecer un ejército de funcionarios administrativos de control conformado por mandos medios, quienes ante el imperio del clientelismo que se afianzó durante el Frente Nacional favorecieron la proliferación las estrategias de acomodamiento frente al Gobierno. Este tipo de agentes administrativos se constituían a la vez en intermediarios entre lo señalado en la política educativa y su puesta en marcha. Los cuerpos de paz, los alfabetizadores, los encargados de implementar los programas de la tecnología educativa e incluso los docentes que trabajarían en los Inem, formaban parte de este pequeño "cuerpo de especialistas" que traería el cambio al país.

A raíz de la experiencia electoral de 1970 se desató un intenso desencanto social. La creciente inconformidad social se nutría del alza en el costo de vida junto con la imposibilidad de acceder a canales concretos de participación. Igualmente, la atmósfera que traía consigo el desmonte legal del Frente Nacional permitía hacerse a la creencia de que asomaban nuevos vientos de cambio y transformación. Sin embargo, este optimismo quedó congelado por dos décadas debido a las tensiones internas causadas por la crítica y el acomodamiento. En este orden de ideas, la politización del sujeto se efectuó mediante enunciados orientados a la promesa de la renovación sobre lo prescrito -ya sea como crítica o acomodamiento al régimen-y el esfuerzo recayó en la configuración de un nuevo sujeto como promesa para el cambio.

Este nuevo hombre que se vislumbraba en el panorama, pero que no logra encontrar un punto para la emergencia, solo eclosionó hacia finales de la década de los ochenta y principios de los noventa, como ha sido planteado hipotéticamente en este trabajo. Sin embargo, si desde finales de la década de los setenta se hablaba de un nuevo hombre en el horizonte de lo social que diera un viraje al orden instituido, ¿qué llevó a que su emergencia se postergará por poco más de una década?

$\mathrm{Al}$ respecto se podrían señalar lo siguiente: por una parte, el imbricado y ambiguo camino de la política se encontraba atado a las maquinarias tradicionales de poder que tenían en el clientelismo y el gamonalismo regional sus formas de supervivencia, lo que propició que durante el desmonte del régimen se mantuvieran mecanismos de coalición implícitos que aseguraban la conservación de la élite y profundizaba la brecha de la exclusión. Ante el asomo de cualquier forma de inconformidad o de insatisfacción social, la excepcionalidad se convirtió en regla mediante el estado de sitio y luego a través del Estatuto de Seguridad. De esta forma, el único medio de acceso fácil y gradual a lugares de administración de lo instituido fue el acomodamiento a los vaivenes de lo política, acción que se facilitaba por la despolitización partidaria que generó la experiencia del Frente Nacional. La apatía y la indiferencia hacia la política, eran complementadas por una disposición que se acomodaba a los lugares de producción de lo político.

Por otra parte, la falta de un discurso que cohesionara las inconformidades y tensiones sociales y las visibilizara por medio de una forma concreta de transformación, llevó a un distanciamiento de las personas hacia toda forma de participación institucional. La emergencia de múltiples proyectos que se abanderaban como depositarios del "verdadero cambio", pero que terminaban encerrados en sus propias torres de marfil y disputas bizantinas, llevaron a un desencantamiento de la política. Se potenció, entonces, la formación de lugares de movilización colectivas que llenaban espacios de vacío de lo institucional, pero terminaban por desbordarlos mediante formas de acción colectivas que apelaban al comunitarismo. Es de anotar que este tipo de acciones no se dan de la noche a la mañana, ya que pueden dormitar en la crítica y la inconformidad social o en el escenario subrepticio de lo institucional y aparecer tan solo en las fugaces manifestaciones de lo contingente.

Aunque la izquierda recurrió a un discurso que buscó la unidad de todas las fuerzas populares con el fin de politizar al sujeto, centró su atención en los papeles sociales que este pudiera desempeñar a lo largo de su vida ya sea como estudiante, obrero, campesino, intelectual, joven, independiente o madre trabajadora, articulándolo a una lógica que asumía la crítica al sistema como mecanismo de acción. Su experiencia no tuvo el impacto deseado y rápidamente se vio envuelta en una atmósfera de dispersión y diferencias irreconciliables.

Es así como hacia 1973, la Unión Nacional de Oposición (UNO) buscó la conformación de una fuerza revolucionaria capaz de impulsar los cambios que la sociedad necesitaba. Sus reivindicaciones giraban en torno a la nación, la tierra y la democracia y aunque fuerza política de corta duración, contribuyó significativamente al posicionamiento de la crítica como forma de politización, particularmente en el campo de lo cívico. La movilización cívica se configura como el terreno en el que reposa la emergencia del sujeto político, de ahí que el viraje del sujeto politizado hacia esta forma de movilización, aunque le haya valido más tiempo posibilitó su eclosión con miras a imprimir un cambio político en el orden instituido. 
La crítica al régimen a lo largo de la década de 1970 toma diversos matices especialmente en relación con la protesta cívica, que si bien no es constante como en la década de los sesenta, sus efectos son mucho más pronunciados. Entre 1958 y 1970 no ocurrieron más de doscientas acciones por año, cuyos picos más altos se dieron entre 1966 y 1969. Por el contrario, durante la década siguiente se dan altibajos notorios, especialmente en los años de 1971, 1975, 1976 y 1977 que sobrepasan las cuatrocientas acciones en el año. En menos de dos décadas (1958-1977) se produjeron ochenta y ocho paros cívicos y si bien en los primeros doce años (1958-1970) se registran solamente dieciséis, para los siguientes seis años su registro fue de setenta y dos (Archila, 2005).

A diferencia de la década de los sesenta durante la cual las acciones reivindicativas y las luchas sociales tenían un matiz claramente clasista que se expresaba en las huelgas de obreros, en los setenta se da un viraje que orienta la movilización hacia acciones y luchas de tipo cívico que apelan a la solidaridad y al humanitarismo. En este sentido, la movilización adquiere rasgos particulares de acuerdo con los tres agentes que sobresalen en ella: campesinos, estudiantes y profesionales (Archila, 1996).

En la primera mitad de la década de los setenta, la crítica estuvo capitaneada por las acciones campesinas especialmente las tendientes a la toma de tierras. Ello debido en parte a las promesas de la reforma agraria del expresidente Lleras Restrepo y a las acciones emprendidas por la Asociación Nacional de Usuarios Campesinos (ANUC), coalición promovida por el Estado. No obstante, la reacción de la elite terrateniente mediante el acuerdo del Chicoral y el fraccionamiento de la izquierda que afectó a la ANUC, terminaron por diezmar la participación de los campesinos en el escenario nacional hacia 1975 (Archila, 1997).

A mediados de la década de los setenta, los estudiantes irrumpen como un segundo agente en las movilizaciones. Ellos, que recientemente habían sido objeto de una proletarización que el discurso prescriptivo les proveyó, emprendieron poco a poco una lucha que perseguía mayores espacios de participación dentro del gobierno universitario y de contera, rechazaban el neocolonialismo y las políticas de intervención del imperialismo norteamericano y emprendían acciones de solidaridad con los sectores obreros y campesinos.

A pesar de su difícil comprensión desde la óptica clasista, los estudiantes marcan algunos rasgos comunes para ese periodo, como la participación de universidades tanto públicas como privadas en las movilizaciones. Sin embargo, la carencia de una agremiación nacional que unificara la organización estudiantil, llevó a una dispersión que finalmente fue aprovechada por las diversas facciones de la izquierda.

Luego de 1975, brota un tercer agente en el contexto de la politización cuyo rasgo principal es ser la punta de iceberg del sujeto politizado, a saber, el profesional, especialmente en los campos de la educación (maestros) y la salud (médicos), sin dejar de lado los funcionarios estatales y del sector bancario que igualmente organizan movilizaciones que no se reducen meramente a maniobras de presión que les proporcione una seguridad ontológi$\mathrm{ca}$, sino que pugnan por una mejora significativa en las condiciones reales de la educación y salud del pueblo. Las acciones emprendidas por el magisterio dan cuenta de las reformas que se gestan en el ámbito educativo y no solo laboral. La solicitud de recursos e infraestructura presionan al Gobierno que responde mediante la diversificación de planes y programas.

Este tercer agente es quien hace más visible este momento de crítica y acomodamiento al sistema, ya que sus reivindicaciones no están inmersas en un discurso puramente prescriptivo aunque haya sido objeto de este. No solo la lucha laboral marca su movilización, sino la búsqueda de mejoras reales en las condiciones de vida colectiva. Las huelgas de maestros, empleados de los seguros sociales y trabajadores bancarios y funcionarios del Estado, apelan a nuevas reivindicaciones que no logran ser captadas totalmente por la izquierda, ni mucho menos por las acciones del Estado.

Pero no toda acción es de crítica al sistema. Bajo la estrategia del acomodamiento se articula el esfuerzo institucional con las necesidades e intereses colectivos de los sujetos, acomodamiento que reforzó una cultura clientelista y de favorecimiento que se jugaba por debajo de la mesa de la legalidad, cuyos orígenes se remontan a las filiaciones y lealtades hacendarias de la Colonia. El sujeto logra acomodarse, entonces, en los pocos e imbricados lugares de participación que la exclusión bipartidista les permitió y así, el juego del clientelismo se reconfigura como el mecanismo extraoficial de intercambio de favores que aseguraba cierto acceso al Gobierno.

El enfoque centrado el establecimiento de un Estado más administrativo que político durante el Frente Nacional, remató en una politización que en últimas "despolitizó" al sujeto. La ausencia de lugares abiertos de confrontación y de discusión de lo político y de mecanismos reales de acceso al sistema, creó las condiciones para escudrińar estrategias que permitieran suplir estas deficiencias. De 
esta manera y de la mano con las acciones colectivas de tipo cívico que se sucedieron a finales de la década de los setenta, acondicionaron el escenario nacional para la emergencia de pautas de instrumentalización de la política que actualizaron el espacio tradicional de la cultura política en la década siguiente. El acomodamiento se constituye en un efecto de este proceso y el sujeto politizado en su protagonista más visible.

A este último momento de crítica y acomodamiento como formas de politización se llega gracias a que durante las décadas de 1950, 1960 y 1970 volúmenes considerables de población pasan de la condición de analfabetos a la comprensión de un escrito y mientras algunos se inician en la metodología del razonamiento en la escuela primaria, importantes contingentes de jóvenes acceden a una educación media cuya función teórica es la preparación cultural, sin olvidar que un sector nada despreciable hizo su ingreso en la enseñanza superior (Rama, 1979). Estos últimos terminan por ser la punta del témpano que sostiene la politización de los sujetos y a la vez son la manifestación más perceptible del sujeto político.

El esfuerzo institucional por educar la creciente masa de población mediante una restructuración del sistema educativo nacional y una modernización del aparato administrativo, hizo posible por una parte, ajustar los recursos humanos a la creciente economía, y por la otra, influir en la formación de un determinado sujeto sobre quien se cimentaron las bases para la transformación del orden instituido.

El sujeto politizado como potencia para la emergencia del sujeto político, se adentra en una multiplicidad de tensiones que moldean su configuración. Entre ellas se encuentra-como efecto del esfuerzo institucional por lo educativo-el establecimiento de una brecha comunicativa entre una población joven educada y sus pares ineducados que hace que el acomodamiento y la crítica al régimen operan como formas de politización gracias a las cuales los primeros logran manifestarse y los últimos quedan relegados al escenario de la participación legal y recurren a formas de expresión que van desde la indiferencia total y la apatía políticas a movilizaciones colectivas y cívicas que toman distancia del Estado sin oponerse a él.

En consecuencia, en la población joven educada sobre la que se instauró la asepsia partidista y el discurso prescriptivo, se fue modelando la figura de un "nuevo hombre" que contribuyera no solo al desarrollo y progreso de la nación, sino a la transformación de la sociedad. La figura del "nuevo hombre" solo tendría posibilidades una vez la crítica y el acomodamiento hicieran su efecto en el sujeto politizado, pues en estas yacen implícitas las fuerzas para la emergencia del sujeto político. Para tal fin, era necesario que la potencia se encontrara en un punto de no retorno en el que la inconformidad, la resistencia y la oposición no solo al Gobierno sino al orden instituido, tuvieran su mayor resonancia, pero a la vez se creara un clima de apatía, indiferencia y ajuste al régimen que terminó por debilitar el asidero de la política. Ante tal grado de insatisfacción social y de letargo de ambos extremos, se gestaron una serie de prácticas y discursos sociales que no solo llenaban los vacíos, sino que desbordaron el sistema, y mediados por el horizonte de la contingencia dieron lugar al sujeto político.

Los esfuerzos por urbanizar y proletarizar al obrero no logran satisfacer lo institucional ni las acciones orientadas por la izquierda. En ambas posturas se refuerza el doble juego de acomodamiento y crítica al sistema, que no solo involucra a la clase obrera sino que es ampliado a los demás agentes de la sociedad, como campesinos, estudiantes, líderes comunales, madres cabeza de familia, profesionales, etc. En este último momento, la politización del sujeto se efectuó mediante los enunciados orientados a la promesa de renovación.

El desmonte del régimen de coalición traía ligada la promesa de ampliación de los espacios de acceso a la administración de lo instituido, los cuales habían sido ocupados por las movilizaciones de tipo cívico. Sin embargo, su posterior preservación en el andamiaje burocrático del Estado y el refuerzo que reciben de parte del Estatuto de Seguridad de Turbay, minan el campo para la emergencia del sujeto político quien debe aguardar hasta mediados de los ochenta para su emergencia en el escenario nacional y de esta forma abrirse a la ficción de un no lugar para lo instituyente.

\section{Discusión}

Esta aventura investigativa es un esfuerzo por pensar la cultura política de los colombianos de la mano con una ontología política del presente, sin reducirse a un trabajo histórico ni mucho menos a una especulación meramente filosófica. Su verdadera razón de ser fue la búsqueda incesante de los modos como se configuró el sujeto en la esfera de lo político. De ahí que a lo largo de él se procuró dilucidar las principales estrategias de conformación y reacción a las prácticas discursivas que se orientaron a la configuración enunciativa a través de lo político y permitieron la emergencia de un sujeto político a finales de la segunda mitad del siglo XX en Colombia. 
La historia social y política de Colombia de la segunda mitad del siglo XX, muestra una serie de luchas y tensiones entre la política, como la administración de lo instituido y lo político, como el momento de lo instituyente. Se delinean las formaciones discursivas que facultan la configuración del sujeto politizado y la emergencia del sujeto político. Como potencia, el primero se configura a través de diversos mecanismos discursivos sobre los que se asienta la conformación de un determinado sujeto que satisfaga las necesidades de quien administra lo instituido, esto es, el Gobierno bipartidista del Frente Nacional; pero también es objeto de formación de quien se opone al régimen. Así pues, mediante la implementación de estrategias discursivas como la asepsia partidista, el discurso prescriptivo y la crítica y el acomodamiento, se hacen los esfuerzos sobre los que este sujeto se constituye. Por su parte, el segundo emerge en el espacio de lo instituyente y persigue la conformación de un orden que desnaturalice y resignifique los sentidos que guían el horizonte de lo político. La Constitución de 1991 es un momento instituyente y su protagonista es el sujeto político en el que confluye una diversidad de luchas por la transformación del orden dado.

Las prácticas discursivas del régimen y de la oposición, confluyeron en la producción de enunciados sobre los sujetos que se esforzaban por limpiar toda violencia partidista y adecuar a los individuos a las necesidades de progreso y desarrollo en el clima de la planeación que experimentaba el país. Esto llevó a la instauración de una lógica de renovación y cambio orientada por la urgente necesidad de ajustar la nación a las demandas de la economía mundial. La búsqueda de mano de obra calificada condujo a acciones emprendidas a diagnosticar y valorar la realidad socioeconómica del país para luego formular políticas orientadas a su mejoramiento. De ahí que el Gobierno recibiera una avalancha de misiones internacionales que se encargaron de estudiar la realidad nacional, cuyas directrices apuntaban a la urgente necesidad de civilizar al obrero. Para ello se establecen dispositivos de formación centrados en la solidaridad y el trabajo comunitario, como la creación e impulso de las juntas de acción comunal y el fortalecimiento de los valores cívicos y patrióticos guiados por la moral católica.

No obstante, ante la incapacidad del Estado para llenar los vacíos de lo social que el crecimiento urbanístico dejaba, se crea un espacio de inconformidad que termina por reivindicar un conflicto de clases. La asepsia partidista mostró que el real movilizador de la violencia era la exclusión social. Miles de individuos que llegaban a la ciudad se convirtieron en sujetos por politizar. El sujeto del enunciado es ahora el obrero inserto en un plan o programa que mejore su vida, de ahí que se busque ciudadanizar al obrero y proletarizar al ciudadano. Los expertos internacionales, los funcionarios y los intelectuales, implementaban estrategias, planes y programas que prescribían o determinaban cómo se debía convertir al campesino llegado a la ciudad en ciudadano. La planeación estratégica como forma de politización, fue un dispositivo que permitió controlar, anticipar y provocar cambios sociales, por lo tanto sirvió como estrategia prescriptiva tanto al régimen como a la oposición. Para el primero, como modo de "urbanizar" al obrero mediante dispositivos como la implementación de planes y programas sociales, el fortalecimiento de las juntas de acción comunal y la creación de los INEM. Para el segundo, para "proletarizar" al obrero por medio de unidades como el programa de partido, la generación de una conciencia revolucionaria, la comprensión de la realidad social mediante una nueva praxis metodológica y la crítica al imperialismo como mecanismo de defensa que fortalece la unidad y las luchas por el derecho a la ciudad.

El esfuerzo del discurso prescriptivo trajo consigo por una parte, la reacción a las políticas educativas, la difícil situación social del país y por tanto la crítica al régimen; y por otra, la acción lenta y desinteresada del Estado ante las acciones emergentes que lo desbordan y las prácticas clientelistas, provocaron que el sujeto recurriera a una especie de pragmatismo.

Todo ello confluyó en una tensión que terminó por proyectar la figura de un "nuevo hombre" que mediante la movilización colectiva lograse fortalecer al máximo el rendimiento del país, de ahí que la movilización cívica se configurase como un escenario en el que dormita la emergencia del sujeto político. Empero, bajo la estrategia del acomodamiento se logró articular el esfuerzo institucional con las necesidades e intereses colectivos de los sujetos. Solo cuando dicho orden se fracturó debido a las confluencias de prácticas sociales que desnaturalizaron los sentidos del orden dado, el sujeto político despertó y encontró en los espacios de inclusión política que emergieron una oportunidad para formar parte del momento instituyente que vivió el país a finales de la segunda mitad del siglo XX.

\section{Referencias}

Archila, N. M. (1996). ¿Utopía armada? Oposición política y movimientos sociales durante el frente nacional. Recuperado de http://goo.gl/pOgrtu

Archila, N. M. (2005). Idas y venidas, vueltas y revueltas: protestas sociales en Colombia, 1958-1990. Instituto Colombiano de Antropología e Historia. 
Archila, N. M. (1997). Protesta social y Estado en el Frente Nacional. Controversia, 170, 9-56.

Ayala-Diago C. A. (1997). Resistencia y oposición al establecimiento del Frente Nacional. En: Análisis Político, 30. Bogotá. IEPRI, Instituto de Estudios Políticos y Relaciones Internacionales. Universidad Nacional de Colombia.

Ayala-Diago C. A. (2008). Exclusión, discriminación y abuso de poder en el tiempo del Frente Nacional. Bogotá. Facultad de Ciencias Humanas. Universidad Nacional de Colombia.

Buenaventura, N. (1973). La clase obrera hacia la unidad. Estudios Marxistas. Revista Colombiana de Ciencias Sociales.

De La Fuente, L., \& Messina, L. (2003). Bajos Fondos del Saber. La Arqueología como método en Michel Foucault. Revista Litorales, 2(2). Recuperado de http://goo.gl/2XaOnr

Organización Marxista Colombiana. (1964). La Organización Marxista Colombiana y la Unidad de la Teoría y la Práctica. Revista de Crítica Contemporánea.

Foucault, M. (1986). ¿Por qué hay que estudiar el poder?: la cuestión del sujeto en la obra colectiva. Materiales de sociología crítica. Madrid: Ediciones La Piqueta,

Foucault, M. (2007). La arqueología del saber. México: Siglo Veintiuno Editores.

Guillen, M. F. (1996). El poder politico en Colombia. Bogotá: Planeta.

Hartlyn, J. (1993). La política del régimen de coalición. La experiencia del Frente Nacional. Bogotá. Tercer Mundo Editores. Ediciones Uniandes. CEI.
Hernández, C. D. (2010). Arqueología del saber y orden del discurso. Un comentario sobre las formaciones discursivas. EN-CLAVES del pensamiento, 4(7), 47-61.

Hobsbawm, E. (2010). Historia del siglo XX. Buenos Aires: Editorial Planeta.

Medina, M. (1977). Los paros en Colombia 1957- 1977. En: Estudios Marxistas. Revista Colombiana de Ciencias Sociales, 14.

Moreno, N. F. (1982). La planeación educativa durante el Frente Nacional. Aportes para su análisis e historia. Bogotá Univ. Pedagógica Nacional.

Múnera, R. L. (1998). Rupturas y continuidades. Poder y movimiento popular en Colombia. 1968-1988. Bogotá: Universidad Nacional de Colombia

Rama, G. W. (1979). Educación y democracia. Revista Colombiana de Educación, 3. Universidad Pedagógica Nacional. CIUP. Semestre I.

Rojas-Ruiz, H., \& Camacho, Á. (1975). El frente nacional: ideología y realidad. Bogotá: Ed. Punta de Lanza.

Sánchez, G., \& Meertens, D. (2006). Bandoleros, gamonales y campesinos. El caso de la violencia en Colombia. Bogotá: Ancora Editores.

Torres, C. A. (1993). La ciudad en la sombra: barrios y luchas populares en Bogotá, 1950-1977. Bogotá: CINEP.

Urbano, J. (1970). Urbanización y acción comunal. En: Estudios Marxistas: Revista Colombiana de Ciencias Sociales, 3.

Zúñiga, M. (1979). ¿Neutralidad ideológica o determinación social en la planeación educativa? Recuperado de http://goo. $\mathrm{gl} / \mathrm{I} 8 \mathrm{eh} 8 \mathrm{~s}$ 